\title{
Viruses in Endodontic Infections
}

\author{
Bharati D Deo ${ }^{1}$, Shashikala $\mathrm{K}^{2}$, Kishore G Bhat ${ }^{3}$ \\ ${ }^{I}$ Dept. Of Conservative Dentistry Govt. Dental College and Research Institute, Bangalore India \\ ${ }^{2}$ Dept of Conservative Dentistry, DAPMRV Dental College, Bangalore, India \\ ${ }^{3}$ Maratha Mandal's NGH Dental College and Research Institute, Belgaum, India
}

\section{Introduction}

Apical periodontitis is an inflammation of the periradicular tissues. The most common causative agents are the microbes that cause infection of the pulp and subsequently the root canal. Bacteria that infect the root canal are the most important causative agents and over 460 different species have been detected. Yeasts have also been associated with periapical inflammation, however despite the detection of various viruses in chronic periapical granulomas, the role of viruses in apical periodontitis has not been clearly understood. ${ }^{1}$ Parra and Slots ${ }^{2}$ and Contreras and Slots ${ }^{3}$ detected several viral transcripts in periodontal pockets using polymerase chain reaction (PCR). This evoked a growing interest amongst various researchers in the association of virus in apical periodontitis. Sabeti et al. ${ }^{4,5}$ hypothesized that concomitant herpesvirus infection may have a role in the development of apical periodontitis, similar to their role in the marginal periodontitis. They showed the presence of herpesvirus in periapical tissues. This article aims at analyzing the available evidence to elucidate the role of virus in apical periodontitis.

\section{History}

Viruses are obligate intracellular parasites and survive only in the presence of viable cells. The scientific study of the viruses and viral infection began at the end of the $19^{\text {th }}$ century. In 1884, Chamberland invented a filter, that was later known as 'ChamberlandFilters', which were used by Ivanovsky to show that the filtered sap of diseased tobacco plants caused disease in healthy plants. In 1898, Martinus called the filtered substance a 'virus' and in 1900, Finlay \& Reed suggested that mosquitoes carried the cause of yellow fever. Louis Pasteur and Edward Jenner developed the first viral vaccine in 1885. Herpes infection was known since the time of Hippocrates and in 1920, Lowenstein confirmed infectious nature of HSV 1\&2. In 1952 Varicella Zoster Virus was detected and named. In 1964, Epstein-Barr and Achong, detected and named the EB virus and this was first virus shown to cause cancer. In 1970, Howard Temin and David Baltimore showed, Reverse transcriptase, the key enzyme used by retroviruses to translate RNA into DNA, which led to development of antiviral drugs, a key turning-point in the history of viral infections. In 1986, HHV-8 was discovered. ${ }^{6}$

\section{Virus In Oral Infection}

Viral infective agents present in the oral cavity belong to the Herpesviridae family. The name of the virus family is derived from the word Herpain. ('to creep') The structure of herpesviruses consists of a doublestranded DNA genome encased within an icosahedral capsid, a proteinaceous tegument and a lipid-containing envelope with embedded viral glycoproteins

The herpes virus are classified as, alpha - herpes simplex virus-1, herpes simplex virus- 2;(HSV 1,2) and varicella-zoster virus; (VZV), beta -cytomegalo virus (HCMV) and human herpesvirus types 6 and 7;(HHV6 and 7) and gamma - Epstein Barr virus(EBV) and human herpesvirus type -8 (HHV-8). ${ }^{7}$ Viruses other than herpesviruses have been found in association with marginal periodontitis. ${ }^{8}$ The human papillomavirus (HPVs) form a group of epithiliotropic virus. They are non-enveloped and have a double stranded structure and they reside in various areas of the body that includes the oral cavity. HPV cause warts and chronic infections of either the skin and oral mucosa. ${ }^{2,9}$.

Herpesviruses are the most communicable infectious viruses in humans and the prevalence of herpesvirus in the adult population worldwide is about $90 \%$. Herpesvirus commonly attacks the mucosa, skin, eyes and nervous system. Primary infection may or may not be clinically evident. After the primary infection, the virus ascends sensory or autonomic nerves at the site of primary infection and persists in neuronal ganglion, which innervates the site, in a latent form. In response to stimuli such as trauma, fever, hormonal imbalance, stress, steroids and chemotherapy, the latent virus is reactivated. Reactivated virus grows in the neuron, travels back down to the site of primary infection and causes recurrent lesions.

\section{Diseases Caused By Herpesvirus}


Herpesvirus cause a wide variety of chronically recurring diseases; recurrent herpes labialis due to herpesvirus-1; half of the affected people suffer multiple attacks annually. Herpes genitalis caused by both herpesvirus 1 and 2, is the most common genital disease in women. Ocular herpes infection by herpesvirus 1 and 2 may lead to blindness due to corneal infection .Herpes encephalitis, is the most sporadic viral disease of the brain caused by herpesvirus 1 in adults and herpesvirus 2 in neonates. Varicella-Zoster virus enters the body via the respiratory route and causes chicken-pox. The rash appears in crops and is mainly on the trunk. The infection is highly communicable. The virus however remains in the latent form in the ganglion. The latent virus when reactivated causes shingles where the eruption of rash is characteristically unilateral. Epstein-Barr viral infection is acquired by oral-oral contact and the disease is called mononucleosis. Patients have fever, pharyngitis, palatal petechiae and cervical lymphadenopathy. Burkitt's lymphoma and nasopharyngeal caricinima are associated with this virus. Transmission of cytomegalovirus may occur via congenital infection, close sexual or oral contact and blood transfusion. This causes pneumonia, rhinitis and hepatits. Herpesvirus-6 cause sudden exanthema and multiple sclerosis, herpesvirus-7 cause exanthema subitum, fever and rash and herpesvirus -8 has been associated with Kaposi's sarcoma, a vasculo-endothelial tumor, especially in immunocompromised cases. ${ }^{10}$

Virions are present in salivary glands, oral mucosa and gingival sulcus and are shed through the saliva. Systemically healthy adults also shed detectable herpesvirus DNA in saliva. The initial herpesvirus infection is followed by a latent phase in host cells, which ensures the survival of viral genome throughout the life of an individual.

Viral infection during the development period of the tooth can adversely affect the teeth. ${ }^{11} \mathrm{CMV}$ infection during the development causes defective peridontium and cemental hypoplasia. During puberty, hormonal changes can cause reactivation of cytomegalovirus (HCMV), suppresion of immune defenses against bacteria and this in turn causes overgrowth of A actinomycetemcomitans, which inhibits epithelial cell proliferation by means of cytolethal toxins.

\section{Residing Of Herpesvirus In The Human Body}

Primary herpesvirus infection is followed by a state of latency in the infected host. They reside in various human cells. Herpes simplex virus 1,2 and varicella zoster virus resides in monocytes and nerve terminations, the Epstein Barr virus resides in B cells and epithelial cells, cytomegalovirus resides in monocytes, macrophages and T cells, herpes simplex virus 6 and 7 in T cells and epithelial cells and herpes simplex virus 8 in B cells, monocytes and epithelial cells. ${ }^{8,12,13}$ Most of these cells are present in the inflammed periradicular tissues and may serve as a source for herpesvirus infection. Herpesvirus infect and replicate into different types of host cells.

\section{Detection of Herpesvirus}

The herpesvirus shave been detected from saliva, sulcular epithelium, symptomatic apical periodontitis lesions, from endodontic abscesses from lesions of HIV positive patients. Since herpesvirus and paplloma virus can be shed in saliva it may be possibility that these viruses also have access to the pulp and periradicular tissue through coronal exposure.

Studies were conducted to examine the presence of herpesvirus in dental pulp. Hanna ${ }^{14}$ detected no herpesvirus from the teeth with acute irreversible pulpitis.

The sampling material for herpesvirus are saliva, abscess aspiration, periapical tissue, gingival tissue and periodontal tissue

The methods used for detection of the virus are culture, immunofluorescent staining, flow cytometry, in-situ hybridization, animal Inoculation and molecular methods (including single and nested PCR, MDA PCR, RT-PCR, and Real-time PCR).

Studies by Andric et al. ${ }^{15}$ revealed the presence of $\mathrm{HCMV}$ in the cystic wall, of both inflammatory and non inflammatory odontogenic cysts. Li et.al. ${ }^{16}$ using RT and Nested PCR for samples from endodontic pathosis detected DNA and RNA of herpesvirus especially of EB virus and cytomegalovirus.

Hannah et al. ${ }^{14}$ using PCR, found no herpesvirus in any of the samples collected from pulpal tissues of teeth with irreversible pulpitis.

Hernadi et $\mathrm{al}^{17}$, detected $72 \%$ DNA and $50 \%$ mRNA of EBV and and 10\% -DNA of CMV, in samples from apical periodontitis. In the study 2,5\% EBV-DNA were detected from healthy controls.

\section{Role Of Herpesvirus In Apical Periodontits}

Apical periodontitis is infectious disease and the major causative agents are bacteria invading the root canal. Due to the detection of various herpesvirus in the symptomatic apical periodontitis lesions, ${ }^{4}$ acute apical abscess, ${ }^{18,7}$ large apical lesions ${ }^{19}$ and lesions from HIV positive patients, ${ }^{19,20}$ it has been hypothesized that herpes virus may have a role to play in the pathogenesis of acute apical periodontitis. The lesion may develop 
as a direct result of virus infections or the viral infection may act as a disease modifier. The disease modifier generally alters the response of the host to the infective agents. The virus can impair the immune response of the host by causing immuno-suppression and this leads to overgrowth of bacteria in the apical part of the root canal 21

Localized inflammation of the apical periodontal tissues causes an influx of host defense cells to the site of inflammation. When these cells are infected with the herpesvirus (latent form), the virus is reactivated either spontaneously, by concomitant bacterial infection or when the resistance of the host is reduced. This way the herpesvirus acts a disease modifier. The effect of disease modifiers helps to understand:-

- Why asymptomatic teeth become symptomatic.

- Why lesions take long to heal after treatment

- Why well treated root canals result in failure

\section{Herpesvirus Mediated Apical Disease}

When the healthy pulp is invaded by bacteria, pulpitis ensues and this gives rise to the influx of inflammatory cells to the site of inflammation. After the primary herpesvirus infection the virus remain in a latent form and resides in the body of the host. These latent cells get reactivated when there is pulpal inflammation. The process is depicted in the FIG-1

\section{Viral Bacterial Association}

Viral bacteria cooperation has been suggested for otitis media ${ }^{22}$ acute respiratory tract infection, ${ }^{23,}{ }^{24}$ and sinusitis ${ }^{25}$ In marginal periodontitis, the subgingival presence of DNA from cytomegalovirus (HCMV) and Epstien-Barr virus (EBV) has been related to the increased occurrence or levels of bacteria responsible for periodontal disease like P. gingivalis, T. forsythia, D. pnumosintes, P. intermedia, P. nigrescens, C. rectus and T. denticola. ${ }^{26-29}$ This observation kindles interest in a possibility of similar association in the case of apical periodontitis. Studies done to search for such association showed that CMV-EBV association with Fusobacterium spp, Streptococcus spp and Parvimonas micra occuring concommitantly in samples from apical periodontitis. 30 and Herpes simplex virus association with T.denticola, D. pneumosintes and T. forsythia in teeth with apical periodontitis. ${ }^{31}$ A study ${ }^{32}$ investigated the possible associations between 9 candidate endodontic pathogens ( Treponema spp, T. forsythia, Porphyromonas spp, Dialister spp, and F. alocis and herpesvirus type 1 to 8 as well as human papilloma virus in acute apical abscess. It was found that all the samples tested positive for the presence of bacteria and two-thirds of the abscess aspirates were positive for the DNA from at least one of the viruses tested. HHV-8 and HPV were the most prevalent viruses in the study and had an association with the target bacteria. HHV-8 was for the first time detected in high frequency. Another study ${ }^{33}$ was conducted to investigate the association between presence of EB virus, human cytomegalovirus and 3 endodontic bacterial pathogens (P. gingivalis, T. denticola and T. forsythia-'red complex'), in samples from acute apical abscesses. It was seen that cytomegalovirus was the most frequent herpesvirus and $\mathrm{T}$. denticola was the most frequent bacterium among the target organisms in acute apical abscesses.

The authors opined that there are two ways of explaining the detection of virus in the abscess samples. One, that the virus may cause severe impairment of host defense and may favor bacterial overgrowth and the second one, that the occurrence is just a epiphenomenon, where bacterial infection causes inflammation and influx of virus-infected inflammatory cells to the area. Some abscess samples testing negative for the target virus may suggest that the epiphenomenon argument holds true. The investigators also inferred that the nested PCR method might have failed to detect the target virus or the virus other than those targeted may have been present.

\section{Host-Virus Interactions}

When a viral infection occurs the host mounts a defense response in the form of Cellular Defense, Intracellular Mediators and Antibodies In the early stage of viral infection is a race between the virus and the host defense system. The non-specific or innate immune defense such as Interferon (IFN), natural killer (NK) cells and macrophages become active.

The Interferon activates the antiviral mechanisms in neighboring cells enabling them to resist virus infection. It activates a number of genes with direct antiviral activity by leading to block in the translation of viral mRNA and triggers apoptosis- suicide of the infected cell, and activates latent endonuclease involved in degrading viral RNA.

Active NK cells are detected within 2 days of a viral infection. They are major effector cells against herpesvirus. They act by mediating direct cytolysis of infected cells and through the production of IFN gamma, which protects cells from infection and activates macrophage antiviral mechanism. 
Macrophages are present in the tissues of the body and act as first line of defense against many pathogens. In virus infection they phagocytose virus and virus-infected cells, killing of virus-infected cells and produce antiviral molecules such as tumor necrosis factor- $\alpha(\mathrm{TNF} \alpha)$, IFN $\alpha$ and nitric oxide.

As the viral infection proceeds adaptive (Specific) immune response starts with the appearance of cytotoxic -T lymphocytes (CTLs), helper T (TH) cells and production of antiviral antibodies ${ }^{34}$

Herpesvirus can trigger an array of host responses that include dysregulation of macrophages, lymphocytes and can downregulate the anti-viral host host immune response. Herpesvirus are able to interfere with the cytokine production to divert the potent antiviral cytokine response by a diverse array of strategies which allow the virus to survive throughout the lifetime of the host. ${ }^{35}$

The results of the studies on detection of herpesvirus and the role they play in the pathogenesis of periapical lesions, point at a strong association of herpesvirus especially reactivation of latent EBV and HCMV with symptomatic apical periodontitis. The presence of virus in a clinical sample does not prove their role in pathogenesis. Herpesvirus can occur in the human defense cells. Future studies for the detection of viral RNA transcripts, high viral titres and proteins and studies based on experimental animal models will help us understand the role of virus in pathogenesis of pericapical lesions. In addition studies on interactions among herpesvirus, bacteria and host immune reactions and the possibility of the inclusion of antiviral agents in endodontic treatment, may be undertaken.

\section{Conclusion}

Detection of herpesvirus DNA in periapical lesions has brought a new dimension to our knowledge of periapical infections. Future research, directed towards, understanding the role of viruses and combating them would be an added step towards our goal of achieving success in endodontic treatment.

\section{References}

[1]. Jakovljevic A, Andric M. Human cytomegalovirus and Epstein-Barr virus in etiopathogenesis of apical periodontitis: a systematic review. J Endod. 2014;40(1):6-15

[2]. Parra B, Slots J. Detection of human viruses in periodontal pockets by PCR. Oral Microbiol Immunol 1996; 11: 289-93

[3]. Contreras A, Slots J. Mammalian viruses in human periodontits. Oral Microbiol Immunol 1996; 11: 381-6

[4]. Sabeti M, Simon JH, Slots J.Cytomegalovirus and Epstein- Barr virus are associated with periapical pathosis. Oral Microbiol Immunol 2003; $18: 327-8$

[5]. Sabeti M, Valles Y, Nowzari H, et al. Cytomegalovirus and Epstein-Barr virus DNA transcriptionin endodontic symptomatic lesions. Oral Microbiol Immunol 2003; 18:104-8

[6]. Wikipedia "History of virology." Wikipedia, The Free Encyclopedia. Wikipedia, The Free Encyclopedia, 12 Feb. 2016. Web. 2 Mar. 2016

[7]. Ferrira DC, Paiva SS, Carmo FL, Rocas IN, Rosado AS, Santos KR, et al. Identification of Herpesviruses Types1-8 and Human Papillomavirus in Acute Apical Abscesses. J.Endod 2011; 37: 10-16

[8]. Slots J. Oral viral infections of adults. Periodontol 2000 2009; 49: 60-86.

[9]. Hormia M, Willberg J, Ruokonen H, et al. Marginal Periodontium as a potential reservoir of human papillomavirus in oral mucosa. J Periodontol 2005; 76:358-63

[10]. Arora DA and Arora B, Text Book of Microbiology $3^{\text {rd }}$ Edition, CBS Publishers, New Delhi-Bangalore, 2008

[11]. Ting M., Contreras A., Slots J. Herpesviruses in localized juvenile periodontitis. J. Periodontal Res. 2000;35:17-25. [

[12]. Grinde B, Olsen I, The role of viruses in oral disease. J Oral Microbiol 2010;2: 21-27

[13]. Contreras A, Slots J. Herpesviruses in human periodontal disease. J Periodontal Res 2000;35:3-16

[14]. Rosaline H, Sachdeva GS, Satish ES, Kandaswamy D. Detection of presence or absence of herpes simplex virus 1, EB virus and human cytomegalovirus in infected pulp using polymerase chain reaction. Endodontology 2007;19:25-30

[15]. Andric M, Milasin J, JovanovicT et al. Human cytomegalovirus is present in odontogenic cyst. Oal Microbiol Immunol.2007;22:347-51

[16]. Li H, Chen V, Chan Y, et al. Herpesviruses in endodontic pathoses: association of EB virus with irreversible pulpitis and apical periodontitis. J Endod 2009;35:23-9

[17]. Hernadi K, Szalmas A, Mogyorosi R, et al. Prevalence and activity of Ebstein-Barr virus and humancytomegalovirus in symptomatic and asymptomatic apical peridontitis lesions. J Endod 2010;36:1485-9

[18]. Chen V, Chen Y, Li H, Kent K, Baumgartner JC, Machida CA, et al. Herpesviruses in abscesses and cellulitis of endodontic origin. J Endod 2009;35:182-8

[19]. Sabeti M, Slots J. Herpesviral-bacterial co-infection in periapical pathosis. JEndod 2004;30:69-72

[20]. Saboia-Dantas CJ, Coutrin de Toledo LF, Sampaio-Filho HR, Siqueira JF Jr. Herpesviruses in asymptomatic apical periodontitis lesions: an immunohistochemical approach. Oral Microbiol Immunol 2007;22:320-5

[21]. Slots J, Sabeti M, Simon JH. Herpesviruses in periapical pathosis: an etiopathogenic relationship? Oral Surg Oral Med Oral Pathol Oral Radiol Endod 2003;96:327-31

[22]. Bakaletz LO. Immunopathogenesis of polymicrobial otitis media. J Leukoc Biol 2010;87:213-22

[23]. Bakaletz LO. Viral potentiation of bacterial superinfection of the respiratory tract. Trends Microbiol 1995;3:110-4

[24]. Sung RY, Chan PK, Tsen T, Li AM, Lam WY, Yeung AC, et al. Identification of viral and atypical bacterial pathogens in children hospitalized with acute respiratory infections in HongKong by multiplex PCR assays. J Med Virol 2009;81:153-9.

[25]. Alho P. Viral infections and susceptibility to recurrent sinusitis. Curr Allergy Asthama Rep 2005;5:477-81

[26]. Contreras A, Umeda M, Chen C, Bakkar I, Morrison JL, Slots J. Relationship between herpesvirus and adult periodontitis and peridontopathic bacteria. J Periodontal 1997;70:478-84

[27]. Saygun I, Kubar A, Ozdemir A, Yapar M, Slots J. Herpesviral-bacterial interrelationships in aggressive periodontitis. J Periodontal Res 2004;39:207-12 
[28]. Slots J, Sugar C, Kamma JJ. Cytomegalovirus periodontal presence is associated with subgingival Dialister pneumosintes and alveolar bone loss. Oral Microbiol Immunol 2002;17:369-74

[29]. Saygun I, Kubar A, Sahin S, Sener K, Slots J. Quantitative analysis of association between herpesviruses and bacterial pathogens in periodontitis. J Periodontal Res 2008;43:352-9

[30]. Sabeti M, Slots J. Herpesviral-bacterial coinfection in periapical pathosis. J Endod 2004;30:69-72

[31]. Nishiyama SA, Makona V, Velasquez-Melendez G, Avila-Campos MJ. Occurrence of herpessimplex virus 1 and 3 priodontal bacteria in patients with chronic periodontitis and necrotic pulp. Can J Microbiol2008;54:326-30

[32]. Ferreira DC, Rocas IN, Paiva SS, Carmo FL, Cavalcante FS, et al. Viral- bacterial association in acute apical abscesses. Oral surg Oral Med Oal pathol Oral Radiol Endod 2011; 112: 264-271.

[33]. Ozbek SM, Ozbek A, Demiray T. Herpesvirus and "red complex" bacterial analysis of acute apical abscesses. 2015, J Dent Probl Solut 2(3)053-057

[34]. Immunilogy ${ }^{\text {h }}$ 2008, 7th Edition, MOSBY -Elsevier. David Male, Jonathan Brostoff, David B Roth, Ivan Roitt

[35]. Sabeti M, Kermani V Sabeti S, Simon JH. Significance of human cytomegalovirus and EB virus in inducing cytokine expression in periapical lesions. J Endod 2012;38:47-50

FIG-1 Herpesvirus Mediated Apical Disease
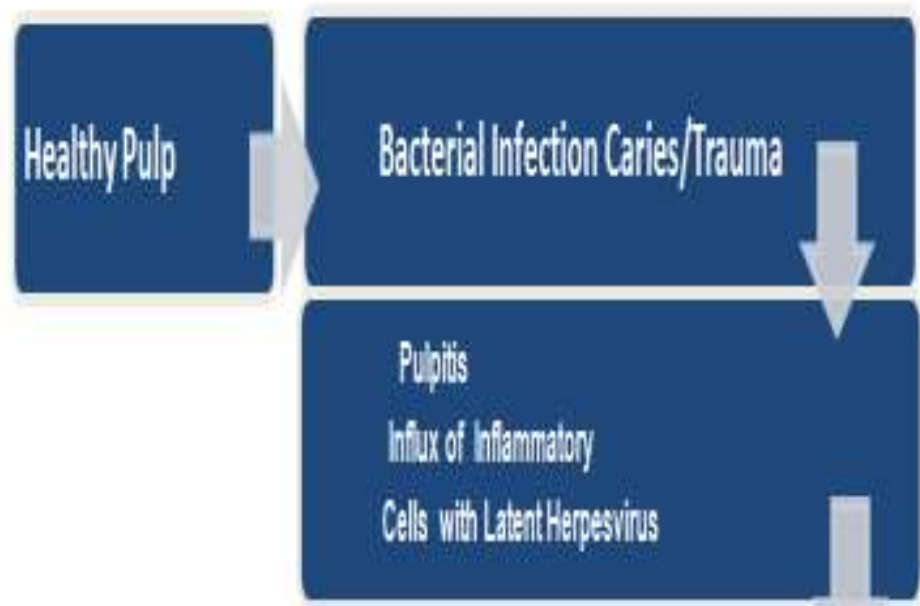

Encowortoptitic Property

gatins /minumosipession,

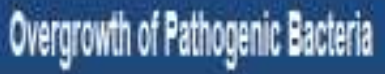

\section{Destrutive Periagial Disease}

